\title{
Modified gastric biopsy forceps as a flexible stylet- assisted nasogastrictube insertion in anesthetized and intubated patients: a prospective randomized controlled study
}

Narut Ruananukun

Ramathibodi Hospital

Amorn Vijitpavan ( $\square$ fluotec@hotmail.com )

Ramathibodi Hospital

Chutima Simasatikul

Ramathibodi Hospital

\section{Research Article}

Keywords: nasogastric tube, insertion, stylet, gastric biopsy forceps, success rate

Posted Date: February 23rd, 2021

DOI: https://doi.org/10.21203/rs.3.rs-146451/v1

License: (c) (i) This work is licensed under a Creative Commons Attribution 4.0 International License.

Read Full License 


\section{Abstract \\ Background}

Insertion of a nasogastric tube in an anesthetized intubated patient may be difficult. A nasogastric tube is prone to coil and kink during insertion. We hypothesize that gastric biopsy forceps can be used as a flexible stylet-assisted nasogastric tube insertion. It can improve the first-attempt success rate over the conventional blind technique during nasogastric tube insertion in the anesthetized intubated patient.

\section{Methods}

Eighty adult patients who required intraoperative nasogastric tube insertions were randomized to the gastric biopsy forceps assisted technique (stylet group) or the conventional blind technique (control group) for insertion of a nasogastric tube. The success rates, the duration of insertion, the incidences of coiling and kinking of a nasogastric tube, and the occurrences of complications were recorded.

\section{Results}

The first-attempt success rate was $92.5 \%$ in the stylet group compared with $65 \%$ in the control group ( $P=$ $0.013)$. The overall success rate was higher in the stylet group ( $100 \%$ vs $85 \% ; P=0.026)$. The mean time required to insert the nasogastric tube was shorter in the stylet group ( $24.85 \pm 9.62$ vs $62.4 \pm 59.38$ seconds; $P=0.002)$. The incidences of coiling and kinking were lower in the stylet group $(7.5 \%$ vs $32.5 \%$; $P=0.005)$. The incidence of minor bleeding was lower in the stylet group, but not statistically significant ( $2.5 \%$ vs $17.5 \% ; P=0.057)$. No other complications were observed in either of the groups.

\section{Conclusion}

The gastric biopsy forceps-assisted nasogastric tube insertion resulted in a higher success rate, less time for insertion, and lower incidence of coiling and kinking of a nasogastric tube than the conventional blind technique in anesthetized intubated patients without serious complications.

\section{Trial registration:}

Thai Clinical Trials Registry (www.clinicaltrials.in.th), TCTR20141018001 (19/09/2014).

\section{Background}

Insertion of the nasogastric tube is easy to do when the patient awake as the patient can co-operate in the swallowing of the nasogastric tube. In an anesthetized intubated patient, the relaxation of pharyngeal 
muscles might be an obstacle. The most common sites of impaction are the piriform sinuses, arytenoid cartilages, and the esophagus which becomes compressed by the inflated cuff of an endotracheal tube [1].

Another important concerning issue is the material of the nasogastric tube, which is usually made of polyurethane or silicone, making it soft and less traumatic [2]. Additionally, there are lateral orifices on the distal part of a nasogastric tube which are weak points and make it easy to coil or kink when encountering an anatomical blockage [1].

The first attempt success rate of nasogastric tube insertion with the conventional blind technique in an anesthetized and intubated patient was only $50-60 \%[3,4]$. Multiple attempts of nasogastric tube insertion might lead to complications such as trauma, bleeding, and unstable vital signs [5].

There was a various way to facilitate nasogastric tube insertion such as neck flexion with lateral neck pressure [4], forward displacement of the larynx [6], frozen nasogastric tube [7], the use of devices such as slit endotracheal tube [4], laryngoscope or video laryngoscope (Glidescope ${ }^{\circledR}$ ) [8], Rusch intubation stylet [9], and esophageal guidewire [10]. Each method can improve success rate around $66-99.2 \%$ which has different strengths and weaknesses $[4,6-15]$.

The gastric biopsy forceps are common instruments in the endoscopic room. Their flexible property, which is neither too rigid nor too soft, like spring that can move forward to the other ways with less trauma when they impact the barrier.

We introduce a new technique and hypothesize that the gastric biopsy forceps can be used as a flexible stylet assisted nasogastric tube insertion by an increase in nasogastric tube rigidity. It can significantly improve the first-attempt success rate over the conventional blind technique during its insertion in anesthetized intubated patients.

\section{Methods}

The study was a prospective randomized controlled study conducted in the operating rooms in Ramathibodi Hospital between October 2014 and January 2015, after approval from Ramathibodi Hospital's Ethics Committee No. 08-57-17 (01/09/2014) and was registered at Thai Clinical Trials Registry (www.clinicaltrials.in.th); No. TCTR20141018001 (19/09/2014). This study was performed in accordance with the declaration of Helsinki and adhered to the applicable CONSORT guidelines. The safety of the gastric biopsy forceps was approved because they were the medical devices which could be reused after the sterilize process.

Inclusion criteria were patients older than 18 years old, ASA physical status I-IV, scheduled for surgery required an intraoperative nasogastric tube insertion, and a fasting time $>6$ hours for solid food or $>2$ hours for clear liquid food. Patients with nasal stenosis, nares obstruction, nasal septal deviation, a nasal 
mass, upper respiratory tract infection, history of corrosive chemical ingestion, previous esophageal surgery, unstable cervical spine, and coagulopathy were excluded.

Written informed consent was obtained from each patient on the day before the operation, then the patient's nostrils were evaluated by size and amount of fog produced on a metal tongue depressor during exhalation.

The patient was monitored for blood pressure, electrocardiography, heart rate, respiratory rate, and pulse oximetry before underwent general anesthesia with anesthetic agents, narcotic, and neuromuscular blocking agents depending on anesthesiologists. The endotracheal tube was placed and fixed. Cuff pressure was measured and adjusted to $25 \mathrm{cmH}_{2} \mathrm{O}$. The nasogastric tube size was selected (Kendall Curity ${ }^{\circledR}$ stomach tube, Levin's type $125 \mathrm{~cm}$ size $14 \mathrm{Fr}, 16 \mathrm{Fr}$, or $18 \mathrm{Fr}$, Kendall-Gammatron Co.,Ltd., Nakorn Prathom, Thailand) according to the patient. The optimal length for the insertion of a nasogastric tube in each patient was determined by the distance from the tip of the nose to the xiphisternum via the tragus of the ear.

Patients were randomized into 2 groups according to computer-generated randomization with sealed envelopes in serial order (Fig. 1).

Operators must have at least 1 year of experience in nasogastric tube insertion in anesthetized patients and had been observed and trained in both techniques before the study began.

The successful placement of nasogastric tube was confirmed by auscultation of a gargling sound over the epigastrium when $10 \mathrm{ml}$ of air was insufflated via nasogastric tube. Final confirmation was manual palpation of the nasogastric tube in the stomach by the surgeon.

If the first attempt failed, the second and the third attempt would be performed by the same procedure. If more than 3 attempts were made, it would consider the failure of insertion. Then, nasogastric tube insertion was rescued by the assistance of a direct laryngoscope with Magill forceps or the other techniques.

The number of attempts, duration of insertion which was defined as the time interval between the first attempt of nasogastric tube insertion into the nostril and the positive gargling sound over the epigastrium or after failed insertion in the third attempts, operator's satisfaction score from a scale 0 to 10 ( $0=$ unsatisfied, $10=$ the most satisfied) were recorded.

Observers who were not participating in the study evaluated the complications immediately after nasogastric tube insertion, at post-anesthetic care unit, and at the ward. Complications were defined as:

1. Minor injury is defined as an abrasion wound with self-limiting bleeding (blood loss of less than 2 $\mathrm{ml}$ ).

2. Moderate injury is defined as an abrasion or laceration wound with $3-5 \mathrm{ml}$ of bleeding which can be stopped by applying pressure on the wound. 
3. Severe injury or life-threatening complications are defined as a laceration wound with bleeding more than $5 \mathrm{ml}$ which required suture, pneumothorax, esophageal, or stomach perforation. If these complications occurred, the surgery consultation would be needed.

\section{Sample size and statistical analysis}

The sample size was calculated using data from the pilot study of 40 patients which showed the first attempt success rate in the stylet group was $95 \%$ and the control group was $70 \%$. To detect this improvement with a power of 0.8 and type I error of 0.05 , at least 36 subjects per group had to be included in the analysis to reject the null hypothesis. A dropout was added and the final sample size was 40 subjects for each group.

Statistical analysis was performed by using SPSS 20.0 for Windows (SPSS Inc., Chicago, IL, USA). Continuous numerical data (age, weight, height, and nasogastric tube insertion time) were analyzed by mean \pm standard deviation. Discrete numerical data (satisfaction score) were analyzed by the median. The normality of distribution was tested by the Shapiro-Wilk normality test. If the distribution of data was normal, an independent t-test would be used to compare variables between the two groups. If the distribution of data was non-normal, the Mann-Whitney $U$ test would be used.

Categorical data (ASA physical status, success rate, failure rate, and, complication rates) were analyzed by the Pearson chi-square test or Fisher's exact test. P-value $<0.05$ was considered statistically significant.

\section{Results}

Eighty patients were enrolled in this study. There were no statistically significant differences in the patient characteristic data (sex, ASA physical status, age, weight, height, and nasogastric tube size) between the two groups (Table 1). 
Table 1

Patient characteristic data

\begin{tabular}{|c|c|c|c|c|}
\hline & & $\begin{array}{l}\text { Stylet group } \\
(n=40)\end{array}$ & $\begin{array}{l}\text { Control group } \\
(n=40)\end{array}$ & P-value \\
\hline \multirow[t]{2}{*}{ Age (years) } & $18-65$ & $16(40 \%)$ & $22(55 \%)$ & 0.075 \\
\hline & $>65$ & $24(60 \%)$ & $18(45 \%)$ & \\
\hline \multirow[t]{2}{*}{ Sex } & Male; $\mathrm{n}$ & $30(75 \%)$ & $29(72.5 \%)$ & 0.799 \\
\hline & Female; $\mathrm{n}$ & $10(25 \%)$ & $11(27.5 \%)$ & \\
\hline \multirow[t]{3}{*}{ ASA physical status } & $\|$ & $5(12.5 \%)$ & $4(10 \%)$ & 0.928 \\
\hline & III & $22(55 \%)$ & $22(55 \%)$ & \\
\hline & IV & $13(32.5 \%)$ & $14(35 \%)$ & \\
\hline Weight $(\mathrm{kg}) ;$ mean \pm SD & & $62.5 \pm 10.29$ & $62.48 \pm 10.89$ & 0.992 \\
\hline Height $(\mathrm{cm})$; mean \pm SD & & $161.59 \pm 7.97$ & $160.58 \pm 7.75$ & 0.566 \\
\hline \multirow[t]{3}{*}{ Nasogastric tube size $(\mathrm{Fr})$} & 14 & $11(27.5 \%)$ & $15(37.5 \%)$ & 0.606 \\
\hline & 16 & $21(52.5 \%)$ & $19(47.5 \%)$ & \\
\hline & 18 & $8(20 \%)$ & $6(15 \%)$ & \\
\hline
\end{tabular}

The first attempt success rate of nasogastric insertion was 92.5\% (37 in 40 patients) in the stylet group which was significantly higher than $65 \%$ (26 in 40 patients) in the control group ( $P=0.013)$. There were three failed nasogastric tube placements on the first attempt in the stylet group, but successful reinsertions were achieved on the second attempt. Failure insertions of a nasogastric tube (more than 3 attempts) were found in 6 patients in the control group (15\%) as Fig. 3.

The mean time required to insert the nasogastric tube was $24.85 \pm 9.62$ seconds in the stylet group which was significantly shorter than $62.4 \pm 59.38$ seconds in the control group at P-value 0.002 (Table 2). 
Table 2

Nasogastric tube insertion data

\begin{tabular}{|c|c|c|c|c|}
\hline & & $\begin{array}{l}\text { Stylet group } \\
(n=40)\end{array}$ & $\begin{array}{l}\text { Control group } \\
(n=40)\end{array}$ & P-value \\
\hline \multirow[t]{3}{*}{ Success within } & 1 attempt & $37(92.5 \%)$ & $26(65 \%)$ & $0.013^{\star}$ \\
\hline & 2 attempts & $3(7.5 \%)$ & $7(17.5 \%)$ & \\
\hline & 3 attempts & - & $1(2.5 \%)$ & \\
\hline \multicolumn{2}{|c|}{ Fail insertion $>3$ attempts } & - & $6(15 \%)$ & \\
\hline \multicolumn{2}{|c|}{ Success rate (\%Total - \%Fail) } & $40 / 40(100 \%)$ & $34 / 40(85 \%)$ & $0.026^{\star}$ \\
\hline \multirow{2}{*}{\multicolumn{2}{|c|}{$\begin{array}{l}\text { Time of insertion (min); mean } \pm \text { SD } \\
\text { (minimum-maximum) }\end{array}$}} & $24.85 \pm 9.62$ & $62.4 \pm 59.38$ & $0.002^{*}$ \\
\hline & & $(14-66)$ & $(15-195)$ & \\
\hline \multicolumn{2}{|c|}{ Satisfaction score $(0-10)$} & $10(5-10)$ & $8(1-10)$ & $<0.001 *$ \\
\hline
\end{tabular}

The most common complication of nasogastric tube insertion was coiling and kinking of the tube which found 3 cases in the stylet group (7.5\%) and 14 cases in the control group (35\%) with P-value 0.003 . And only minor complications were found in 1 patient of the stylet group and 7 patients of the control group, but there was no statistical significance (Table 3).

Table 3

Complications of nasogastric tube insertion

\begin{tabular}{|lllll|}
\hline & & $\begin{array}{l}\text { Stylet group } \\
(\mathbf{n = 4 0 )}\end{array}$ & $\begin{array}{l}\text { Control group } \\
(\mathbf{n = 4 0 )}\end{array}$ & P-value \\
\hline Coiling & & $3(7.5 \%)$ & $14(35 \%)$ & $0.003^{\star}$ \\
\hline Injury & Minor & $1(2.5 \%)$ & $7(17.5 \%)$ & 0.057 \\
\hline & Moderate & - & - & - \\
\hline & Severe & - & - & - \\
\hline \multirow{2}{*}{$* \mathrm{P}<0.05$; Data are number $(\%)$ unless otherwise stated. } \\
\hline
\end{tabular}

\section{Discussion}

Various techniques to facilitate nasogastric tube insertion in anesthetized patients have been described. According to a review of literature, an esophageal guidewire and Rusch intubation stylet are 2 methods that improve the first attempt success rate to $\geq 90 \%[9,10]$. 
Kirtania $\mathrm{J}$ et al. used an esophageal guidewire with manual forward laryngeal displacement and the first attempt success rate was $99.2 \%$ [10]. After this article was published, there were reports of lung complications, such as tracheal insertion, pneumothorax, and carinal bleeding [11]. They might cause by the spring-tipped end of the esophageal guidewire remains outside the nasogastric tube and the body of the esophageal guidewire is too rigid. These problems were cautioned in our study. Tip of gastric biopsy forceps was kept at the end of the nasogastric tube and their biopsy mouth could not open within the nasogastric tube. The entire body of gastric biopsy forceps has spring-like flexibility, so they are not too rigid and less trauma.

Tsai YF et al. used The "Rusch" intubation stylet tied with a nasogastric tube by Highwayman's hitch. The first attempt success rate was $94.3 \%$. The "Rusch" intubation stylet was originally designed for tracheal intubation which stylet length might be insufficient in some cases and had to be tied outside the nasogastric tube. Although researchers had claimed that the Highwayman hitch was easy to perform and allow for a quick release, there was a case that the Highwayman's hitch unexpectedly untied during the procedure [9].

The obstacle to the insertion of the nasogastric tube is due to its soft properties lead to coil and kink. The solution could be an increase in its rigidity. Chun $\mathrm{DH}$ et al. made a silicone nasogastric tube rigid by filling distilled water and freezing. But distilled water inside the nasogastric tube melted quickly on contact with body temperature led to leak and fill the oral cavity causing fluid aspiration [7]. And there were reports of modified special devices such as ureteral guidewire which the first attempt success rate was $66 \%$ (overall success rate 92\%) [4], Fogarty catheter [12], guitar string [13], angiography catheter [14], and endoscopic equipment [4], but they almost were reports or letters to the editor to suggest techniques without experimental study.

The other method, for instance, laryngoscope and Glidescope ${ }^{\circledR}$ [8] or digital guidance to navigate nasogastric tube [15] had a limitation in a patient with restricted mouth opening. Flexible stylet could be a benefit in these patients. In this study, six patients in the control group required rescue technique by direct laryngoscope and Magill forceps after the failure of the third attempt insertion which 2 of 6 patients were failed insertion by laryngoscope but succeeded insertion by this flexible stylet. Moreover, after this study, we suggested the surgeons use this flexible style in patients with esophageal stricture who failed to insert the nasogastric tube with gastroscopy and guidewire under fluoroscopy, they succeeded more than 10 cases to use it instead of the guidewire without any complications after they checked with gastroscopy and fluoroscopy. However, we suggest to use it carefully with an expert surgeon or endoscopist under fluoroscopy.

The time for the successful placement of nasogastric tube insertion in the control group was significantly longer than that of the stylet group. The reason might be the first attempt success rate in the control group was lower than the stylet group resulted in a longer time interval. If only the time for the first attempt successful placement is considered, it might be no different. 
The limitation of this method was coiling which found 3 of 40 patients in the stylet group. The stylet was unable to remove from the nasogastric tube. The experiment was performed and found that if the unit of the nasogastric tube with the stylet was too much bent in the stomach or coiled in the mouth or the pharynx, the stylet would be struck in the nasogastric tube. The solution was made by little withdrawn the whole unit of the nasogastric tube and try to remove the stylet again or reinserted. The optimal length of the nasogastric tube with the stylet must be measured from the tip of the nose to the xiphisternum via the tragus of the ear, not to the stomach, and further insert the nasogastric tube to the stomach after the stylet is removed.

Complications were found only minor injuries with self-stopping bleeding. This complication could be lessened by prepared patients' nostrils with a vasoconstrictor such as ephedrine.

No patient in either group had moderated or severe or any life-threatening complications from the nasogastric tube insertion procedure in this study. After this study, we had used this stylet for the nasogastric tube insertion in more than 100 patients over 1 year and the patients did not have any severe complications, so we suggest that the safety profile of the modified gastric biopsy forceps as a flexible stylet technique was acceptable. Nevertheless, further study with more sample size should be performed to detect the incidences.

\section{Conclusion}

The gastric biopsy forceps assisted nasogastric tube insertion resulted in a higher success rate, less time for insertion, and lower incidence of coiling and kinking than the conventional blind technique without serious complications in anesthetized intubated patients. They will be an alternative accessory instrument to help the nasogastric tube insertion in anesthetized intubated patients or difficult insertion patients.

\section{Abbreviations}

ASA: American Society of Anesthesiologists

\section{Declarations}

\section{Data Availability Statement}

The datasets used and analyzed during the current study are available from the corresponding author upon reasonable request.

\section{Ethics Approval and consent to participate}

The study was approved by the Ethics Committee of Faculty of Medicine Ramathibodi Hospital, Mahidol University, Bangkok, Thailand, number 08-57-17 (01/09/2014) and was registered at Thai Clinical Trials 
Registry (www.clinicaltrials.in.th); number TCTR20141018001 (19/09/2014). This study was performed in accordance with the declaration of Helsinki and adhered to the applicable CONSORT guidelines. Written informed consent was obtained from all participants.

\section{Consent to publication}

Not applicable

\section{Author Contributions}

All authors were responsible for the conception and design of the study. NR, AV, and CS were responsible for the collection of data. NR analyzed and interpreted data. NR and CS drafted the manuscript and approved the final version. All authors read and approved the final manuscript.

\section{Funding}

This study was funded by Ramathibodi Hospital, Mahidol University, Thailand. This study received no specific grant from any funding agency in the commercial sector.

\section{Acknowledgments}

The authors acknowledge the effort of the entire site investigating team for making this work possible and Dr. Varinee Lekprasert for language editing.

\section{Competing Interests}

The authors declare that they have no competing interests.

\section{References}

1. 1. Ozer S, Benumof JL. Oro- and nasogastric tube passage in intubated patients: fiberoptic description of where they go at the laryngeal level and how to make them enter the esophagus. Anesthesiology. 1999; 91: 137-43.

2. 2. Boyes RJ, Kruse JA. Nasogastric and nasoenteric intubation. Crit Care Clin. 1992, 8: 865-78.

3. 3. Bong CL, Macachor JD, Hwang NC. Insertion of the nasogastric tube made easy. Anesthesiology. 2004; 101: 266.

4. 4. Appukutty J, Shroff PP. Nasogastric tube insertion using different techniques in anesthetized patients: a prospective, randomized study. Anesth Analg. 2009; 109: 832-5.

5. 5. Fassoulaki A, Athanassiou E. Cardiovascular responses to the insertion of nasogastric tubes during general anaesthesia. Can Anaesth Soc J. 1985; 32: 651-3.

6. 6. Perel A, Ya'ari Y, Pinzon R. Forward displacement of larynx for nasogastric tube in insertion in intubated patients. Crit Care Med. 1985; 13: 204-5. 
7. 7. Chun DH, Kim NY, Shin YS, Kim SH. A randomized, clinical triall of frozen versus standard nasogastric tube placement. World J Surg. 2009; 33: 1789-92.

8. 8. Moharari RS, Fallah AH, Khajavi MR, Khashayar P, Lakeh MM, Najafi A. The GlideScope facilitates nasogastric tube insertion: a randomized clinical trial. Anesth Analg. 2010; 110: 115-8.

9. 9. Tsai YF, Luo CF, Illias A, Lin CC, Yu HP. Nasogastric tube insertion in anesthetized and intubated patients: a new and reliable method. BMC Gastroenterol. 2012; 12: 99.

10. 10. Kirtania J, Ghose T, Garai D, Ray S. Esophageal guidewire-assisted nasogastric tube insertion in anesthetized and intubated patients: a prospective randomized controlled study. Anesth Analg. 2012; 114: 343-8.

11. 11. Moon HS, Kang JM, Chon JY. Beware of lung complications when using guidewire-assisted nasogastric tube insertion. Anesth Analg. 2013; 116: 263-4.

12. 12. Rosenberg H. A new technique for inserting nasogastric tubes during anesthesia. Anesthesiology. 1975; 42: 632.

13. 13. Matsuki A, Zsigmond EK. Simple and reliable method of inserting a nasogastric tube during anaesthesia. Br J Anaesth. 1972; 44: 610.

14. 14. Ghatak T, Samanta S, Baronia AK. A new technique to insert nasogastric tube in an unconscious intubated patient. North Am J Med Sci. 2013; 5: 68-70.

15. 15. Mahajan R, Gupta R. Another method to assist nasogastric tube insertion. Can J Anesth. 2005; 52: 652-3.

\section{Figures}




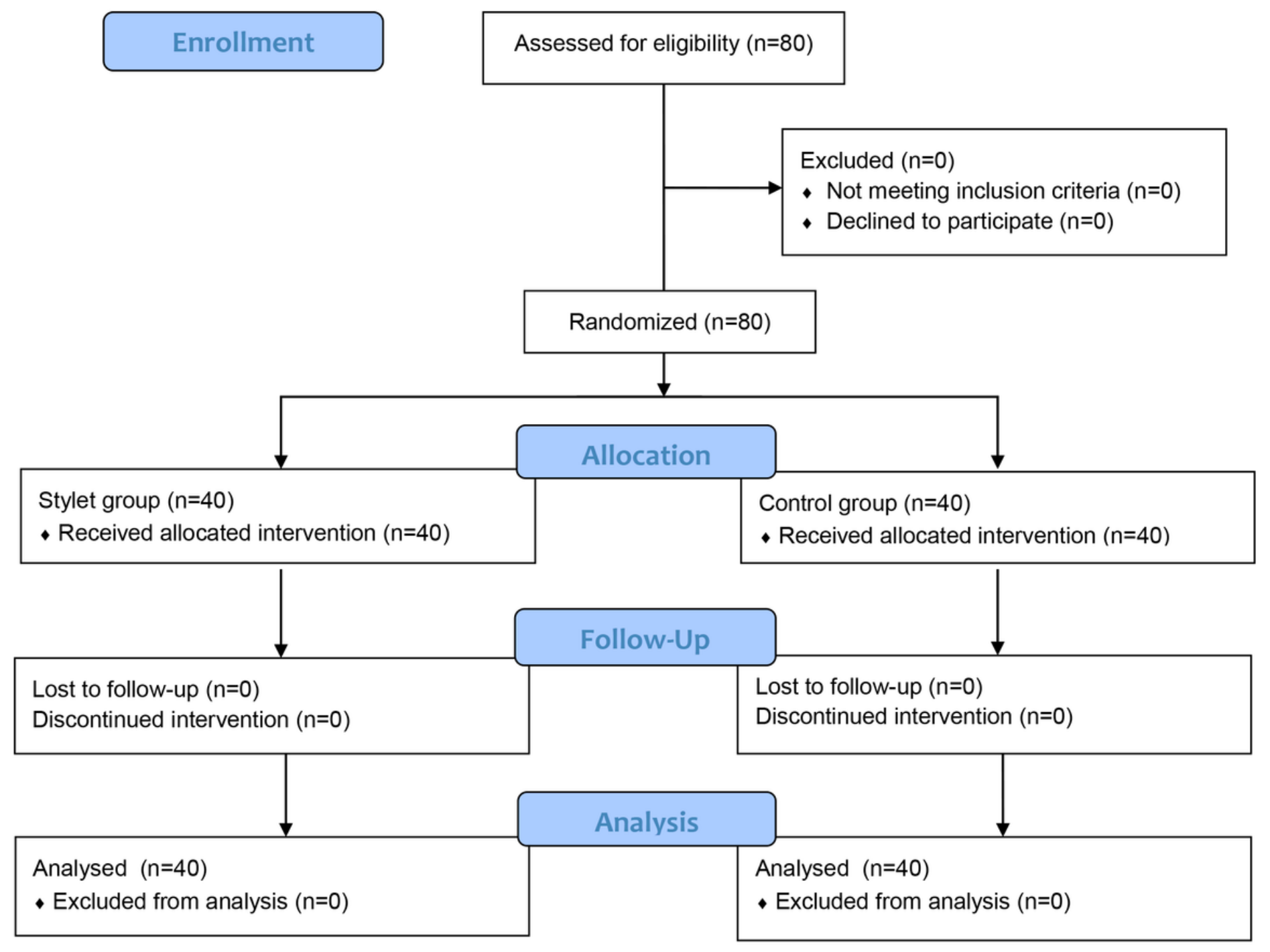

\section{Figure 1}

CONSORT Flow Diagram - Control group: Nasogastric tube insertion was performed by lifting a jaw and inserting a lubricated nasogastric tube via selected nostril until the optimal length was reached. $\cdot$ Stylet group: A gastric biopsy forceps (ENDO-FLEX® $160 \mathrm{~cm}$, ENDO-FLEX GmbH, Voerde, Germany) was used as a flexible stylet. The nasogastric tube with flexible stylet was prepared by inserting a decontaminated, and lubricated flexible stylet into a nasogastric tube in which the tip of the stylet must be kept within the end of the nasogastric tube and recap another end of the nasogastric tube to fix the stylet. Nasogastric tube insertion was performed by lifting a jaw and inserting a lubricated nasogastric tube with flexible stylet via selected nostril until the optimal length was reached. The stylet was withdrawn by removing the cap of the nasogastric tube and straight pulling the stylet. If the stylet can't be withdrawn, the nasogastric tube with flexible stylet should be pulled up a little and the stylet should be tried to withdraw again (Fig. 2). 

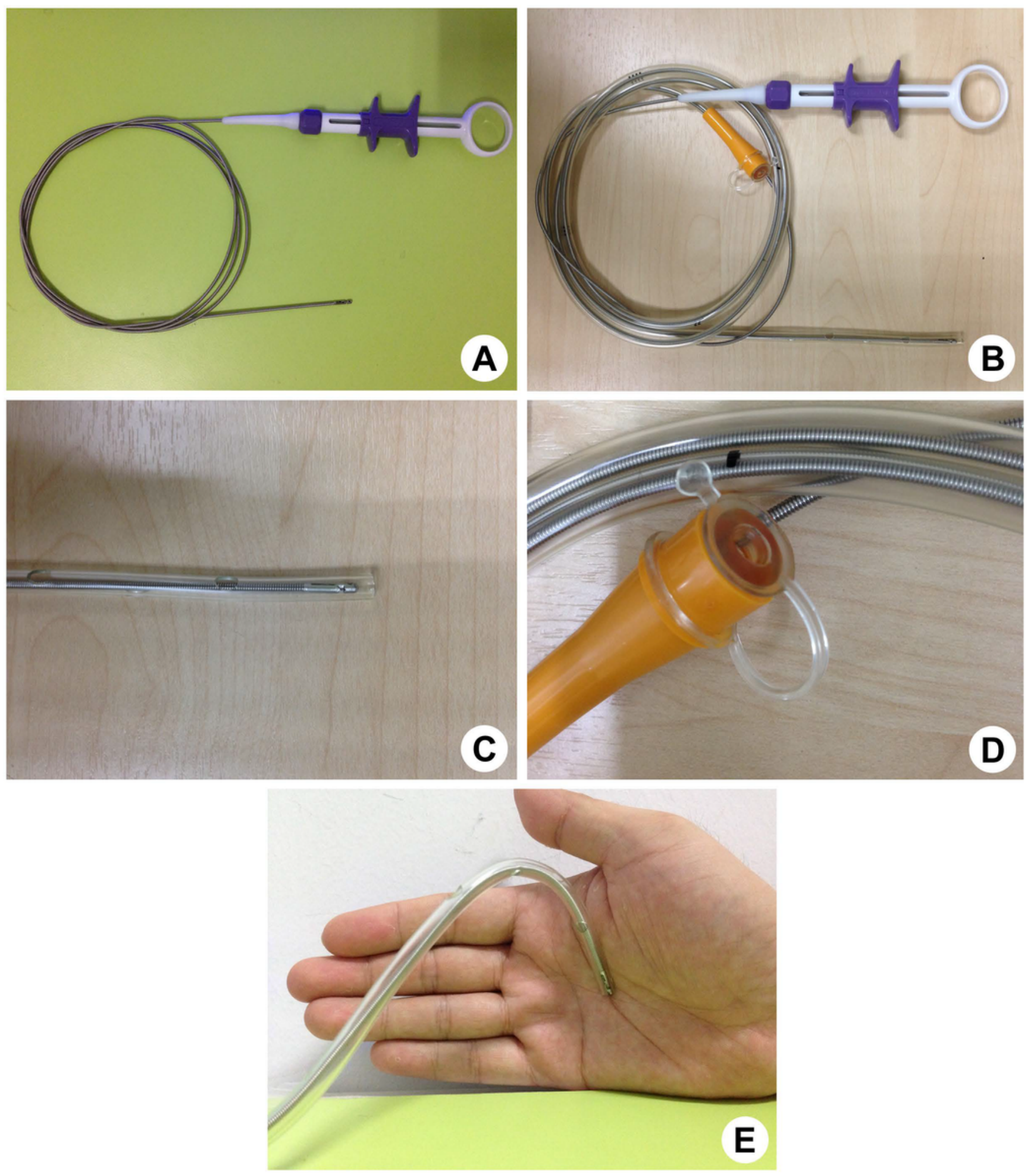

\section{Figure 2}

Gastric biopsy forceps and nasogastric tube A Gastric biopsy forceps B Final preparation of nasogastric tube with the flexible stylet C Tip of the flexible stylet is kept within the end of the nasogastric tube $D$ Recap of another end of the nasogastric tube to fix the flexible stylet E Flexibility of a nasogastric tube with the flexible stylet 


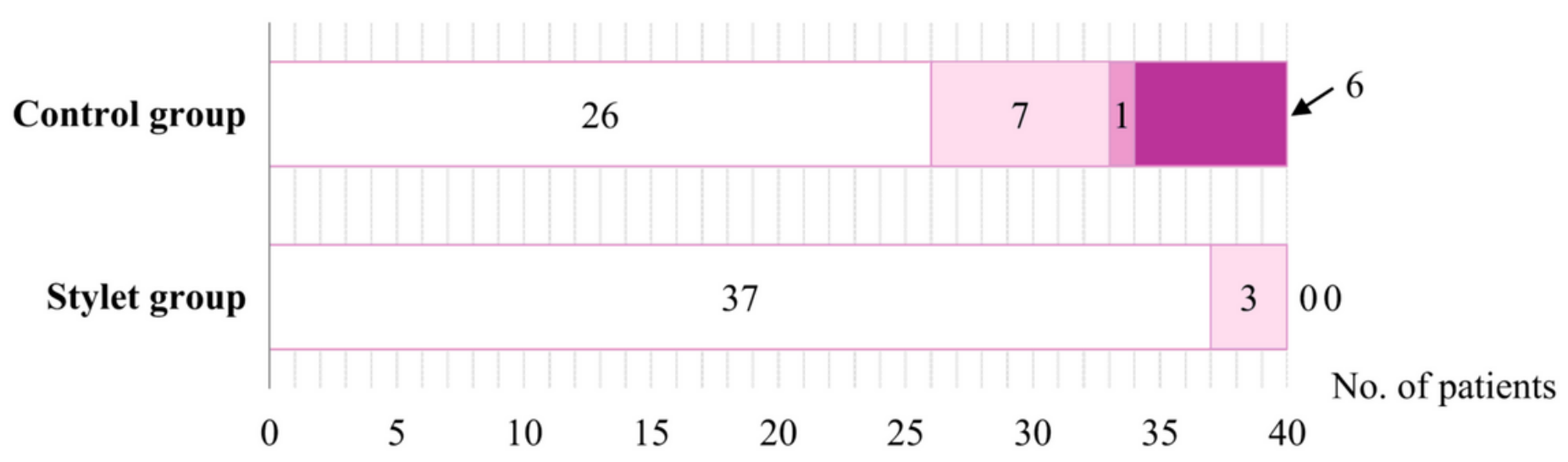

$\neg$ First attempt $\square$ Second attempt $\quad \square$ Third attempt $\quad \square$ Over third attempt or fail

Figure 3

Nasogastric tube insertion success rate 